\title{
POST CONSTRUCTION EFFECT OF BRIDGES ON MORPHOLOGY OF RIVER BRAHMAPUTRA
}

\author{
Nayani Deka ${ }^{1}$ and Dr. Pankaj Goswami ${ }^{2}$
}

\begin{abstract}
The purpose of bridge construction is to ensure and facilitate the communication over the flow of waterways conveniently.However, these structures have detrimental effects on the hydrology and morphology of the adjacent area of the streams as the waterways is constricted. In this project the effect of construction of bridges on river morphology is the major consideration.In this report Brahmaputra River and its three bridges namely as Saraighat, Koliabhomora, Naranarayan bridge is taken as the study area. Bridge pier construction has already been completed before the present study and some severe morphological response has been observed.This study is carried out to determine the section on $\mathrm{d} / \mathrm{s}$ of bridges where erosion may be maximum after the construction of bridges and thus bank erosion protective measures to be adopted simultaneously during the time of construction of bridges.A mathematical model is developed to study the relationship between bank erosion, corresponding distance from bridge site, velocity of river at the bridge site and diameter of piles. In this study the simulated result was analyzed with Arc GIS. The result may vary with the river but approach would be the same to resolve this type of difficulties in all rivers and water way.
\end{abstract}

Keywords - Bridge Construction, Morphology, Brahmaputra River, Pier,Bank Erosion, Mathematical Model, Arc GIS

\section{INTRODUCTION}

Understanding of river behavior on downstream of bridges help in their proper planning, design and maintenance. Morphology of the Brahmaputra River and its aggradation/degradation process has been discussed with reference to flow of water and sediments in the river. Hydraulic analysis is made of the river behavior downstream of bridges as a result of sediment deposition upstream and inadequate energy dissipation due to skewed hydraulic jump downstream. Proper understanding of river behavior in the vicinity of the brides is extremely important in their planning, design and maintenance apart from the safety of the structures. They obstruct the normal waterway. On the downstream side of the structures, there is degradation due to release of water with less sediment load and residual kinetic energy flow with higher turbulence. Depending upon the extent of constriction and location of the structure in the flood plain, the approaching river may often be unstable and asymmetric. In such case the river may shift its location and wander anywhere within the flood plain resulting in erosion of bed and banks. Costly training works are required to prevent the possible shift in the existing river course and outflanking of the structures.

\section{METHODOLOGY AND EXPERIMENTATION}

The bank erosion observed to attain a new dimension after construction of bridges. The erosion was found to be high at some downstream section after such construction. This phenomenon leads to this study. The study consists of two parts: the laboratory investigation and the field data analysis. For the project work, the river morphology before and after bridge construction was studied by analyzing with arc GIS. Satellite images of the Brahmaputra river corridor were identified and selected for the study. The images selected were taken during the dry season (NovemberDecember) when cloud-free imagery was available and when water level,vegetation cover and other ground conditions were relatively consistent. The focused extent of the area for this analysis covered the entire Brahmaputra River from Dhubri to Tezpur which is approximately $293 \mathrm{~km}$ as shown in Figure1.

${ }^{1}$ Department Of Civil Engineering, Assam Engineering College, Jalukbari, Guwahati-781013, Assam.

${ }^{2}$ Department Of Civil Engineering, Assam Engineering College, Jalukbari, Guwahati-781013, Assam. 


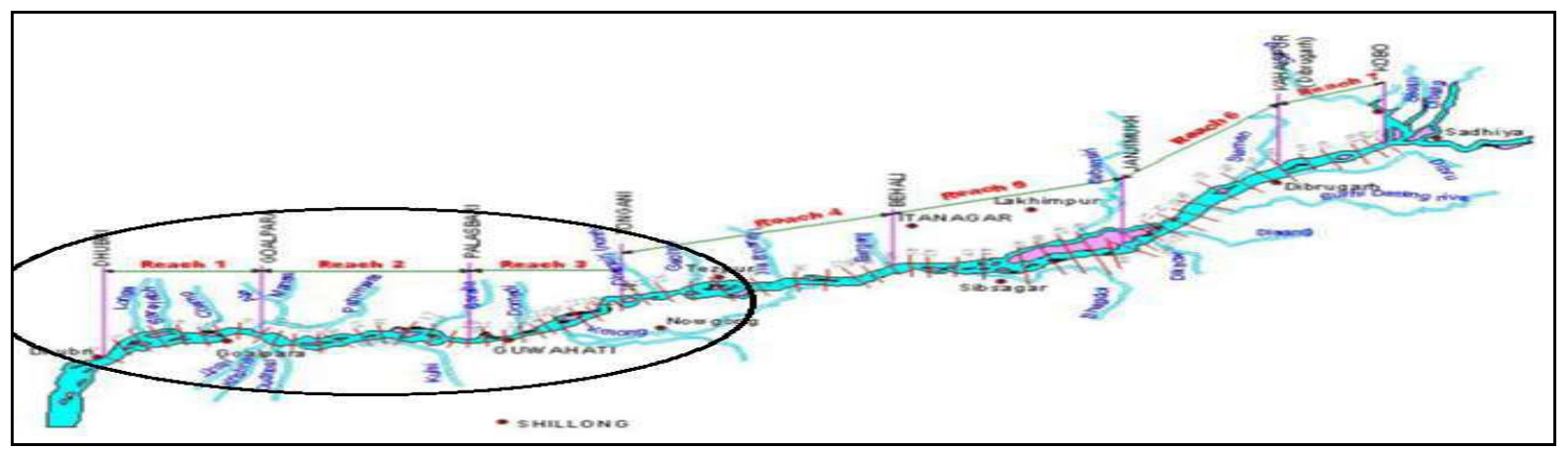

Fig 1-Brahamputra River- from Dhubri to Kobo (Source-SlideShare.com)

Firstly, the maps for river Brahmaputra were downloaded for each of the bridge sites using Google Earth, right from 1985 to 2016. The bank line of the Brahmaputra river is demarcated from each set of imageries and the channel patterns are digitized using Arc GIS software and the change in bank pattern at intervals of 10 years each were studied. Using the maps from ArcGIS, the erosion was calculated and the corresponding distance from the bridge at which the erosion occurred. The process was repeated for all the bridge sites at intervals on 10 years each.

To study the relation between bank erosion, corresponding distance from bridge site, velocity of river at bridge site and diameter of pier, a model study were conducted on a flume of hydraulics laboratory at Assam engineering college. The model of river along with adjacent embankment was constructed with erodible river sand of $96 \mathrm{~cm}$ wide and modeling the bridge site conditions on it. The banks were made $25 \mathrm{~cm}$ wide on each side, hence leaving 46 $\mathrm{cm}$ for the flow of water. The length was fixed at $1000 \mathrm{~cm}$. The model bridge was set up at $200 \mathrm{~cm}$ from the start of the channel. Now, seven sections at a distance of $20 \mathrm{~cm}, 140 \mathrm{~cm}, 260 \mathrm{~cm}, 380 \mathrm{~cm}, 500 \mathrm{~cm}, 620 \mathrm{~cm}$, and $740 \mathrm{~cm}$ from bridge site were considered at which readings were taken.

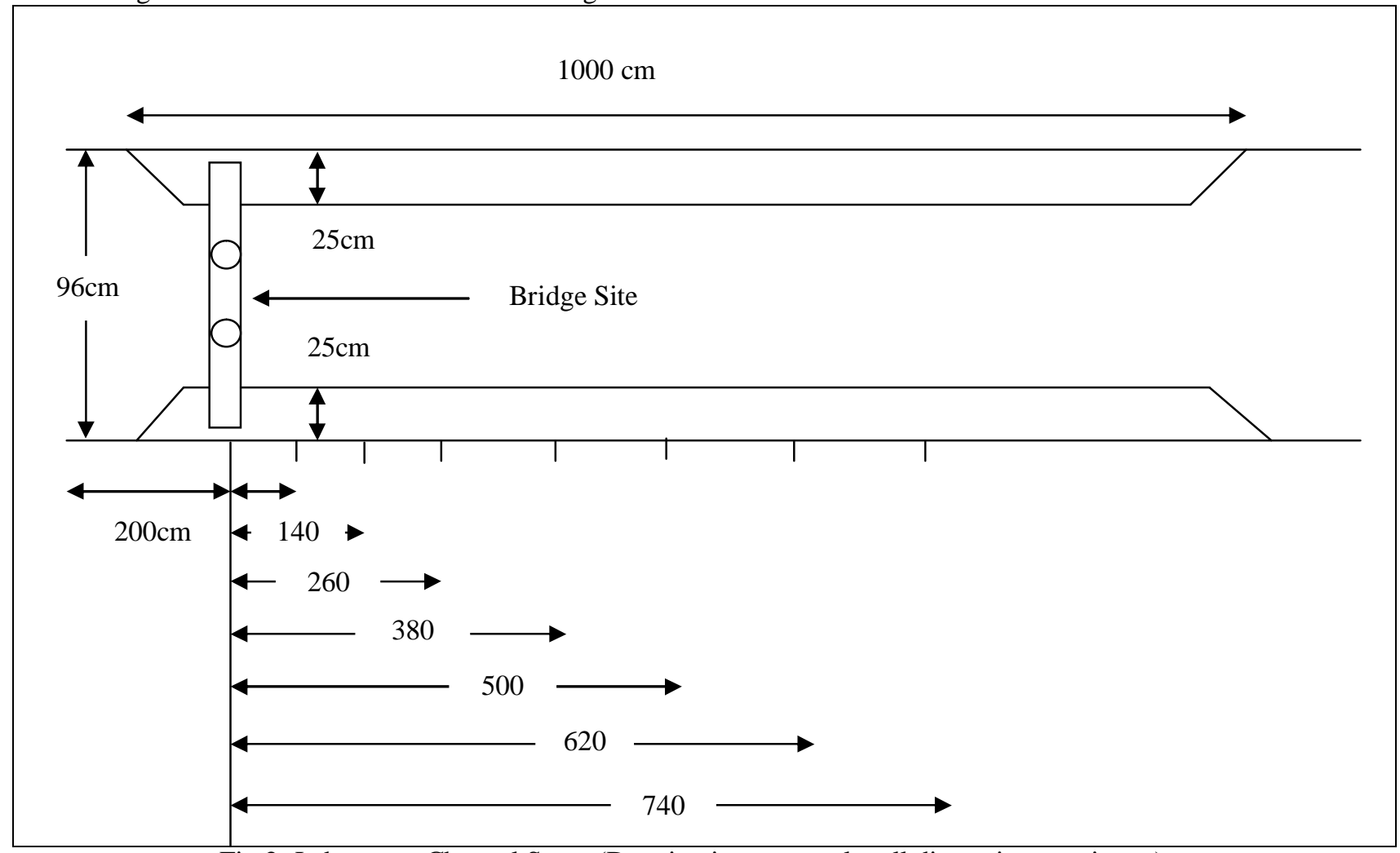

Fig 2- Laboratory Channel Setup (Drawing is not to scale- all dimensions are in $\mathrm{cm}$ )

Firstly,the flow was allowed with no bridge condition.One pump of capacity $10 \mathrm{HP}$ was used which is supplying water at a velocity of $0.38 \mathrm{~m} / \mathrm{sec}$ on the channel and water was pumped continuously for 3 hours;readings for erosion and distance were being taken at an interval of $1 \mathrm{hr}$.The same process was repeated with increase in velocity 
by using two pumps of capacity $10 \mathrm{HP}$ and $7.5 \mathrm{HP}$ which is delivering water at a velocity of $0.5846 \mathrm{~m} / \mathrm{sec}$. The water was pumped for 3 hours continuously, readings taken at one hour interval at the corresponding sections. Now the flow was observed after constructing a bridge with two numbers of pier of diameter $1.5 \mathrm{~cm}$ and reading were taken for one pump and two pump system respectively at an interval of one hour upto three hour. The same procedure was repeated for pier of diameter $2.5 \mathrm{~cm}$ and readings were taken at corresponding sections. Using the experimental data obtained from the laboratory work, an equation was formulated between distance of erosion from bridge site,corresponding erosion, diameter of the piers and velocity of flow of water.The data obtained from ArcGIS was then used to validate the equation obtained from the laboratory work.

\section{RESULTS AND DISCUSSION}

The study area for the Saraighat bridge comprising of bridge site along with a distance of upto $2.179 \mathrm{~km}$ from bridge site in downstream end. Similarly for Koliabhomora bridge and Naranarayan Setu considering a distance upto 8.707 $\mathrm{km}$ and $5.154 \mathrm{~km}$ respectively from the respective bridge site towards the downstream end. The bank lines were overlapped for 1985 and 2016 to check the probable places of erosion and the corresponding distance from the site. The process was repeated for all the three bridge sites and the erosion and corresponding distance from the site was found out. This data has been tabulated as below. The following maps show the erosion measured from the bridge site at different locations. The data like velocity at the bridge sites, diameter of pier, number of pier are collected from North-Eastern Frontier Railway (Bridge section).Section X-X represents the bridge site, and the sections A-A, $\mathrm{B}-\mathrm{B}$, and $\mathrm{C}-\mathrm{C}$ represent the locations at which erosion is measured from the site.

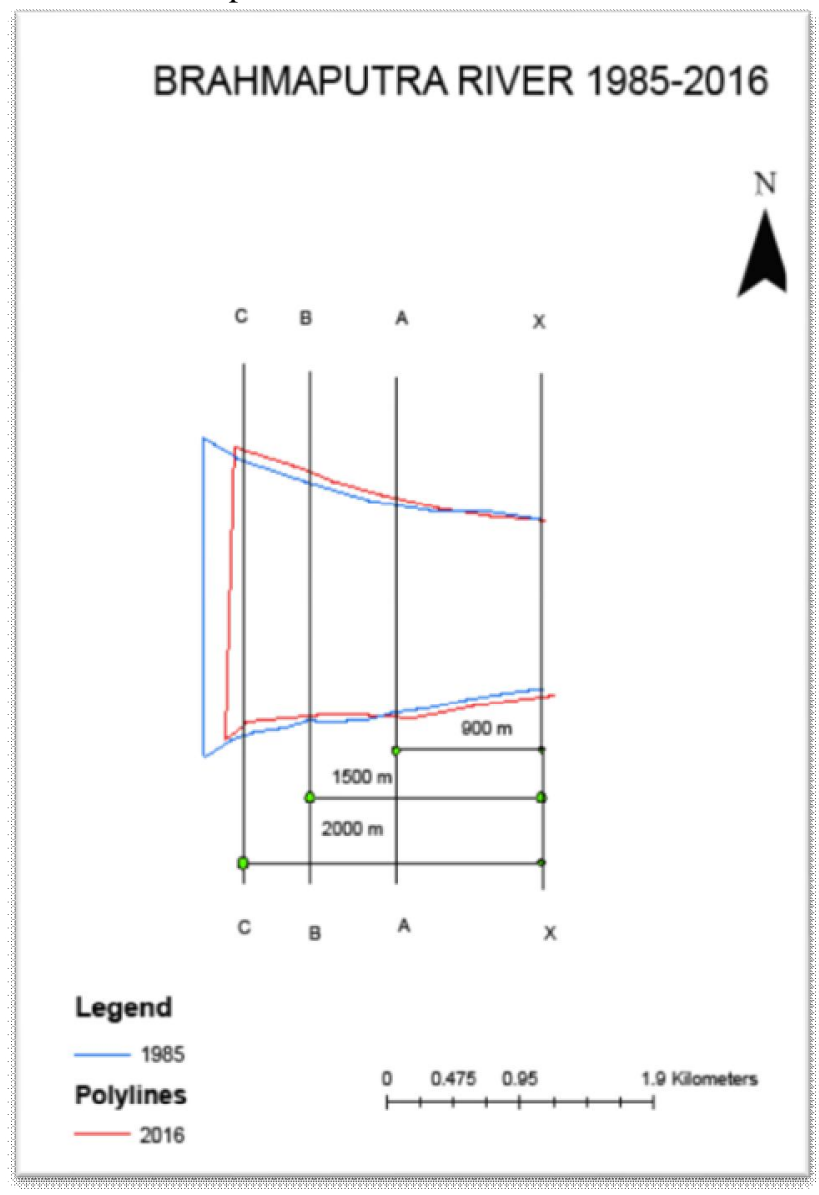

RIVER BRAHMAPUTRA 1985-2016
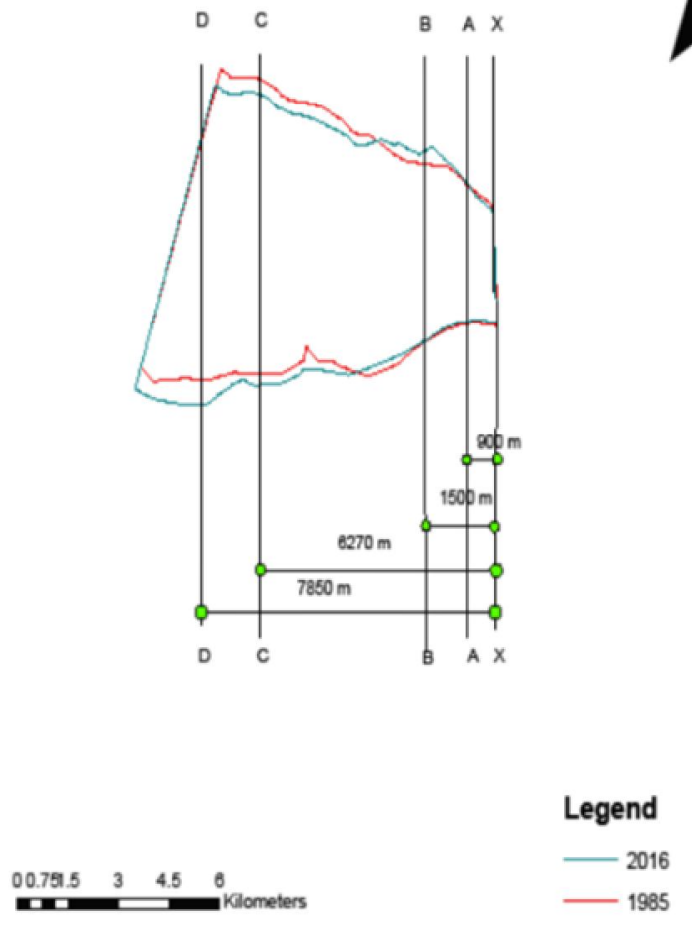

Fig.3-Brahmaputra River near Saraighat Bridge

Fig.4-Brahmaputra River near Koliabhomora Bridge 


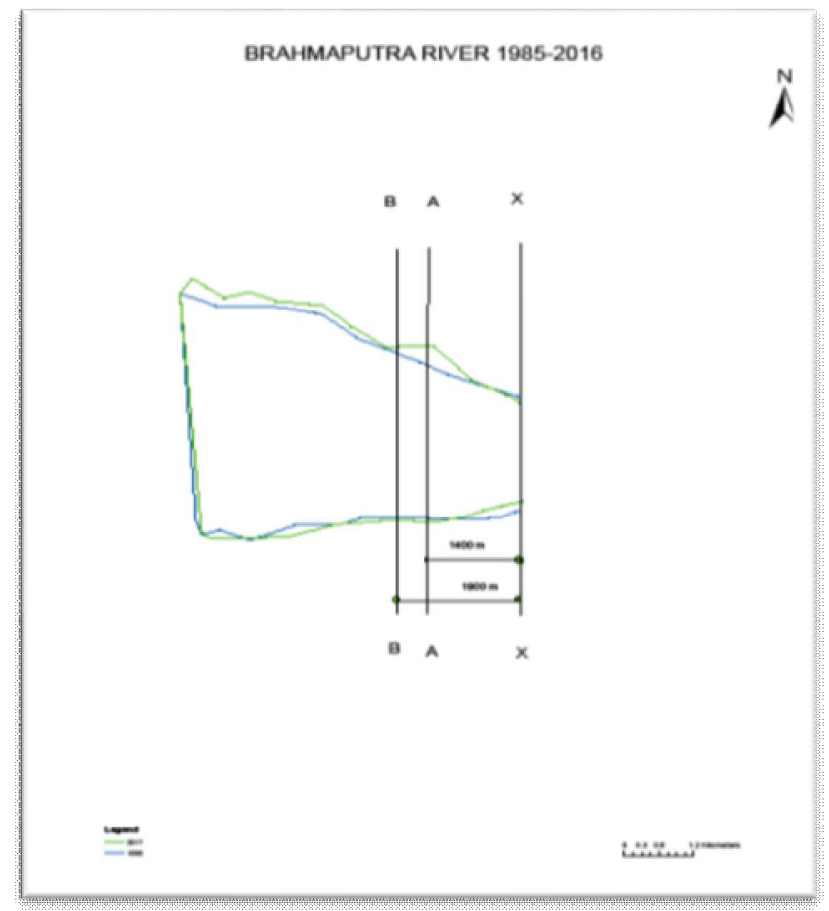

Fig.5-Brahmaputra River near Naranarayan Setu

The experimental setup consists of modeling the real situation in the laboratory. The erosion is measured at 7 different locations from the site for different situations, once without bridge (i.e., before construction of bridge) and once with bridge (i.e.,after bridge construction) of $1.5 \mathrm{~cm}$ diameter and $2.5 \mathrm{~cm}$ diameter, all situations being assessed under two different velocities i.e. $0.38 \mathrm{~m} / \mathrm{sec}$ by using one pump of capacity $10 \mathrm{HP}$ and $0.5846 \mathrm{~m} / \mathrm{sec}$ by using two different pumps of capacity 7.5 HP and 10 HP.The readings taken for erosion and distances have been tabulated.

\begin{tabular}{|l|l|l|l|l|}
\hline No of pier & Velocity $(\mathrm{m} / \mathrm{sec})$ & Pier diameter $(\mathrm{m})$ & Distance $(\mathrm{m})$ & Erosion $(\mathrm{m})$ \\
\hline 2 & 0.38 & 0 & 0.2 & 0.115 \\
\hline 2 & 0.38 & 0.015 & 0.2 & 0.13 \\
\hline 2 & 0.38 & 0.025 & 0.2 & 0.135 \\
\hline 2 & 0.5846 & 0 & 0.2 & 0.125 \\
\hline 2 & 0.5846 & 0.015 & 0.2 & 0.14 \\
\hline 2 & 0.5846 & 0.025 & 0.2 & 0.145 \\
\hline 2 & 0.38 & 0 & 1.4 & 0.09 \\
\hline 2 & 0.38 & 0.015 & 1.4 & 0.105 \\
\hline 2 & 0.38 & 0.025 & 1.4 & 0.11 \\
\hline 2 & 0.5846 & 0 & 1.4 & 0.1 \\
\hline 2 & 0.5846 & 0.015 & 1.4 & 0.115 \\
\hline 2 & 0.5846 & 0.025 & 1.4 & 0.12 \\
\hline 2 & 0.38 & 0 & 2.6 & 0.08 \\
\hline 2 & 0.38 & 0.015 & 2.6 & 0.095 \\
\hline 2 & 0.38 & 0.025 & 2.6 & 0.1 \\
\hline 2 & 0.5846 & 0 & 2.6 & 0.09 \\
\hline & 0.5846 & 0.015 & 2.6 & 0.105 \\
\hline
\end{tabular}




\begin{tabular}{|c|c|c|c|c|}
\hline 2 & 0.5846 & 0.025 & 2.6 & 0.11 \\
\hline 2 & 0.38 & 0 & 3.8 & 0.075 \\
\hline 2 & 0.38 & 0.015 & 3.8 & 0.09 \\
\hline 2 & 0.38 & 0.025 & 3.8 & 0.095 \\
\hline 2 & 0.5846 & 0 & 3.8 & 0.085 \\
\hline 2 & 0.5846 & 0.015 & 3.8 & 0.1 \\
\hline 2 & 0.5846 & 0.025 & 3.8 & 0.105 \\
\hline 2 & 0.38 & 0 & 5 & 0.07 \\
\hline 2 & 0.38 & 0.015 & 5 & 0.085 \\
\hline 2 & 0.38 & 0.025 & 5 & 0.09 \\
\hline 2 & 0.5846 & 0 & 5 & 0.08 \\
\hline 2 & 0.5846 & 0.015 & 5 & 0.095 \\
\hline 2 & 0.5846 & 0.025 & 5 & 0.1 \\
\hline 2 & 0.38 & 0 & 6.2 & 0.065 \\
\hline 2 & 0.38 & 0.015 & 6.2 & 0.08 \\
\hline 2 & 0.38 & 0.025 & 6.2 & 0.085 \\
\hline 2 & 0.5846 & 0 & 6.2 & 0.075 \\
\hline 2 & 0.5846 & 0.015 & 6.2 & 0.09 \\
\hline 2 & 0.5846 & 0.025 & 6.2 & 0.095 \\
\hline 2 & 0.38 & 0 & 7.4 & 0.055 \\
\hline 2 & 0.38 & 0.015 & 7.4 & 0.07 \\
\hline 2 & 0.38 & 0.025 & 7.4 & 0.075 \\
\hline 2 & 0.5846 & 0 & 7.4 & 0.065 \\
\hline 2 & 0.5846 & 0.015 & 7.4 & 0.08 \\
\hline 2 & 0.5846 & 0.025 & 7.4 & 0.085 \\
\hline
\end{tabular}

Using the data obtained from the laboratory experiments, an equation was formulated by using XLSTAT relating bank erosion, corresponding distance from bridge site, velocity of river at the bridge site and diameter of piers.

\section{$\mathrm{D}=19.99-313.19 * \mathrm{E}+196.58 * \mathrm{~d}+6.81 * \mathrm{~V}+912.43 * \mathrm{E}^{2}-3305.03 * \mathrm{~d}^{2}$}

Where E- bank erosion at the downstream end of bridge site in $\mathrm{m}$

D- Corresponding distance of erosion from bridge site in $\mathrm{m}$

$\mathrm{V}$ - Velocity of river at the bridge site in $\mathrm{m} / \mathrm{sec}$

d- Diameter of pier in $\mathrm{m}$

This equation was used to validate the data obtained from ArcGIS and hence, the utility of the equation was checked.This equation is valid when the distance is less than or equal to $2 \mathrm{~km}$. To find the distance of erosion at a greater distance more data and further study is required.

The erosion data obtained after digitizing the map from google earth at the three bridge sites of the Brahmaputra river are summarized below-

\begin{tabular}{|l|l|l|l|l|l|l|}
\hline $\begin{array}{l}\text { No of } \\
\text { piers }\end{array}$ & $\begin{array}{l}\text { Velocity } \\
(\mathrm{m} / \mathrm{s})\end{array}$ & $\begin{array}{l}\text { Pier diameter } \\
(\mathrm{m})\end{array}$ & $\begin{array}{l}\text { Distance } \\
(\text { observed })(\mathrm{m})\end{array}$ & $\begin{array}{l}\text { Erosion } \\
(\mathrm{m})\end{array}$ & $\begin{array}{l}\text { Distance } \\
(\text { calculated })(\mathrm{m})\end{array}$ & Bridge site \\
\hline 11 & 5.0 & 14.0 & 900 & 26.74 & 962.59 & Saraighat bridge \\
\hline 11 & 5.0 & 14.0 & 1500 & 26.73 & 1447.32 & Saraighat bridge \\
\hline 11 & 5.0 & 14.0 & 2000 & 26.71 & 2416.23 & Saraighat bridge \\
\hline 21 & 5.0 & 18.0 & 1400 & 34.35 & 1432.91 & Naranarayan setu \\
\hline
\end{tabular}




\begin{tabular}{|l|l|l|l|l|l|l|}
\hline 27 & 4.0 & 12.0 & 900 & 22.94 & 557.59 & $\begin{array}{l}\text { Koliabhomora } \\
\text { bridge }\end{array}$ \\
\hline 27 & 4.0 & 12.0 & 1500 & 22.91 & 1803.20 & $\begin{array}{l}\text { Koliabhomora } \\
\text { bridge }\end{array}$ \\
\hline
\end{tabular}

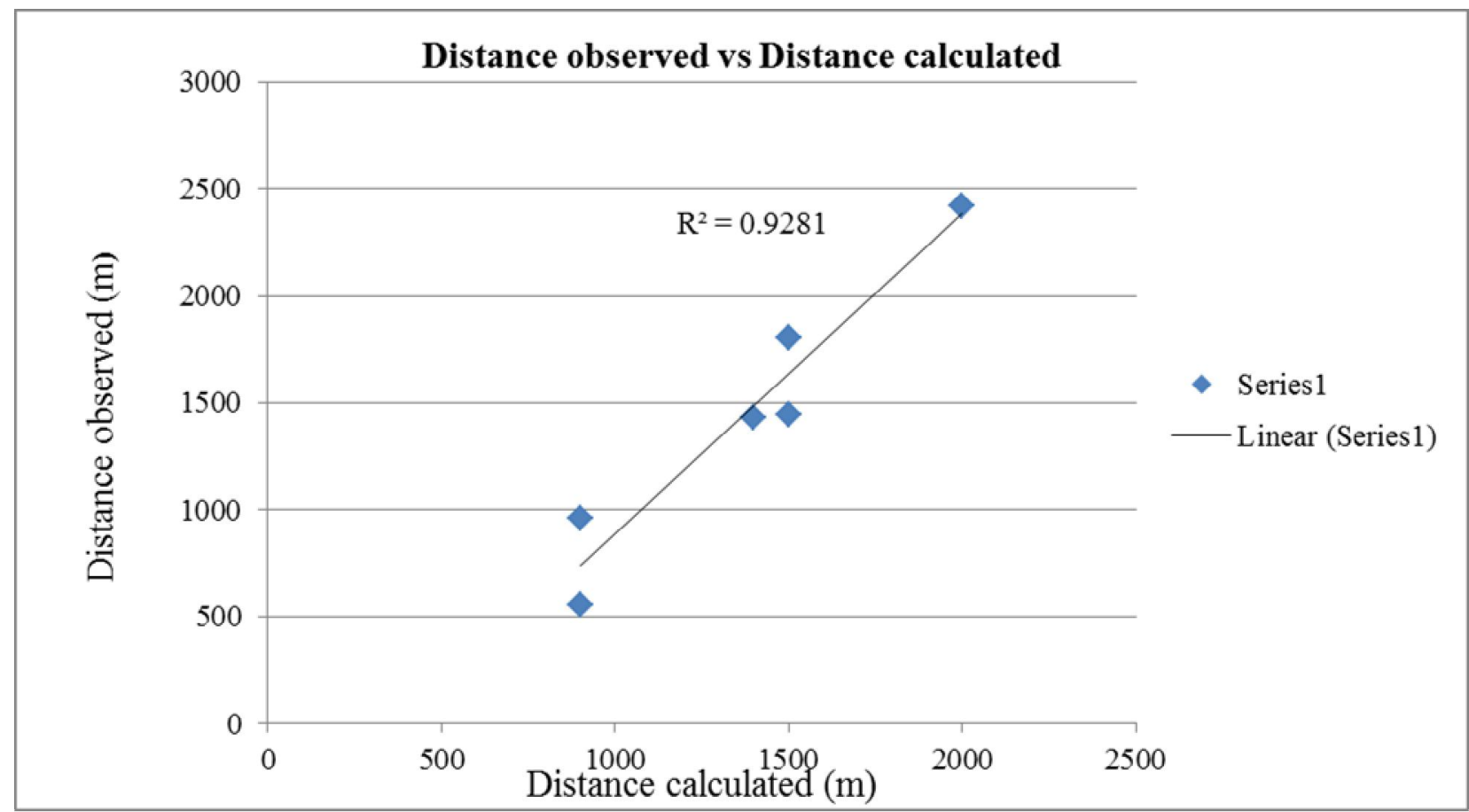

From the above analysis and graph a good agreement was observed between calculated and observed data upto a distance of $2 \mathrm{~km}$ on downstream of bridge site.Hence the equation can be utilized for gathering information regarding distance where the extra precautionary measures to be adopt in the event of construction of bridge on river Brahmaputra.However before adopting the suggested equation a detailed investigation is recommended.

\section{IV.CONCLUSION}

Bridge is an important construction in the line of communication but the construction of such bridges across a river may lead to reduction in waterway resulting excessive bank erosion as well as scour. From the historical data analysis it was observed that at certain section on downstream of the bridges undergoes severe bank erosion causing shifting of river lines which may also become danger to the constructed bridges. Considering that effect this study aims to optimize the section on downstream where maximum bank erosion may occur and the subsequent measures that to be adopted at the construction of bridges. Thus the effect of construction of bridges on the bank line erosion has been evaluated and the erosion pattern studied. With the purview of the study, the following conclusions have been drawn:

1. From the morphological study during 1985- 2016 in all the constructed three bridges observed that there has been a considerable change in the morphology of the river Brahmaputra due to the construction of the bridges.

2. The bank line erosion has shown considerable change due to the construction of the bridges on the river Brahmaputra, in some cases several kilometers from the original position.

3. The equation has been formulated to study the erosion on the banks at different distances and can be helpful in studying the erosion pattern on the banks of river Brahmaputra at the three bridge sites, i.e., Saraighat Bridge, Naranarayana Setu and Kaliabhomora Bridge.

4. Once it is possible to locate the maximum vulnerable section the protective measures to be adopted at such section simultaneously with the construction of bridges to reduce the possibility of bank line shifting.

5. The bank line erosion due to construction of bridges is observed to be maximum in north bank (Refer fig 6 \& 7) 


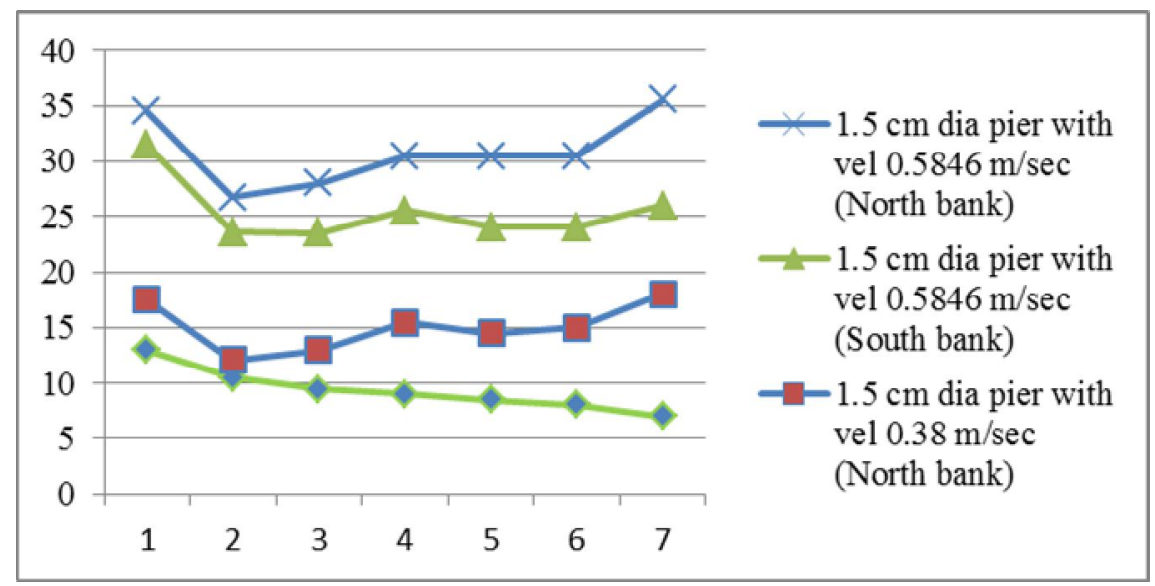

Fig 6- Shifting of bank line in north and south bank for $1.5 \mathrm{~cm}$ dia of pier

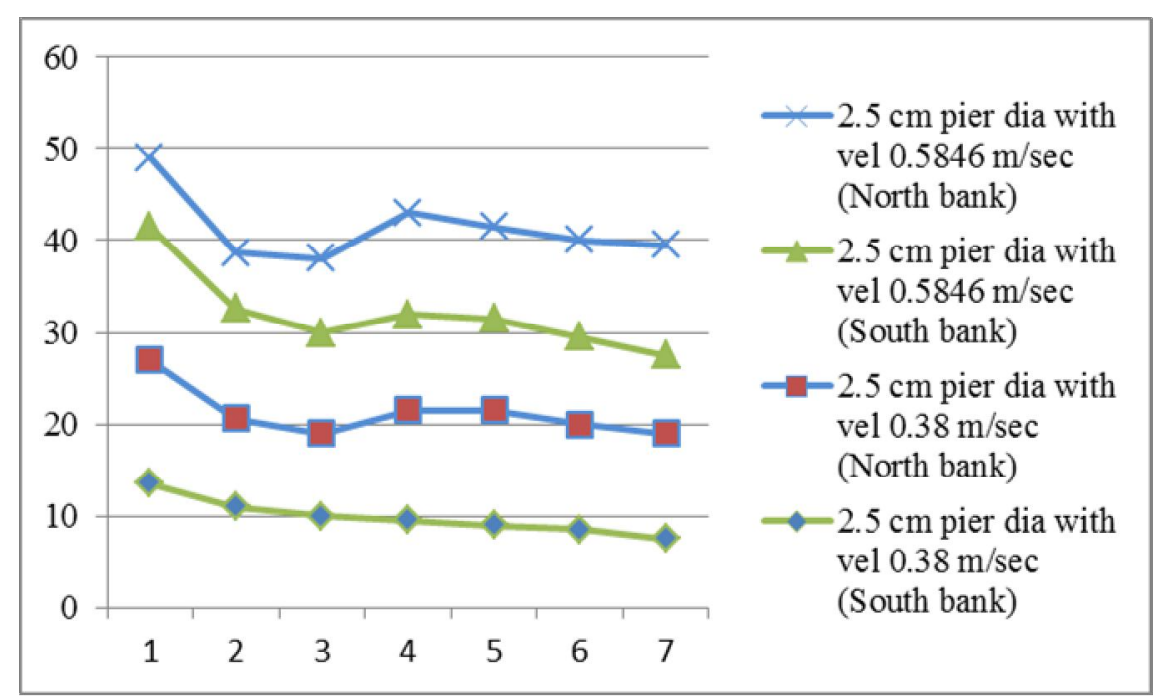

Fig 7- Shifting of bank line in north and south bank for $2.5 \mathrm{~cm}$ dia of pier

\section{REFERENCES}

[1]. Blench, T. (1957) "Regime Behavior of Canals and Rivers" Butterworth Scientific Publishing, London

[2]. Chitale, S.V. (1981), ": Shape and Mobility of River Meanders” Proc. XIXCongross of IAHR, Vol. 2, pp 281-286, New Delhi

[3]. Chitale, S.V. (2000) "Future of the Kosi River and KosiProject'J. of Institution of Engineers (I) Vol. 81, Dec, 99 109114

[4]. Diplas, P. (1990), “Characteristics of Self Formed Straight Channels” J. of Hyd.Engg., ASCE, Vol. 116, No. 5.

[5]. Blench, T. (1957) "Regime Behavior of Canals and Rivers" Butterworth Scientific Publishing, London

[6]. Chitale, S.V. (1981), “: Shape and Mobility of River Meanders" Proc. XIX Congross of IAHR, Vol. 2, pp 281-286, New Delhi

[7]. Chitale, S.V. (2000) "Future of the Kosi River and Kosi Project'J.of Institution of Engineers (I) Vol. 81, Dec, 99 109114

[8]. P. Kotoky, D. Bezbaruah, J. Baruah and J. N. Sarma, "Nature of Bank Erosion along the Brahmaputra River Channel, Assam, India," Current Science, Vol. 88, No. 4,

[9]. Mazumder, S.K. (1993) "River Erosion Downstream of a Barrage" Proc. on "River Scour" org. by CBI \& P at Varanasi, 28-29 April

[10]. Mazumder, S.K. (1993), "Stability of River Downstream of Hydraulic Structures" Proc. of VIII APD- IAHR Congress, Vol II org by CW\&PRS Pune, Oct. 20-23, pp 273-282 
[11]. Mazumder, S.K. and Praveen Kumar (1995) "Local Scour Downstream of a Level Apron with and without Hydraulic Jump" Proc. 6th International Symposium on River Sediments and org. by CBI \& P, New Delhi, Nov. 7-11

[12]. Mazumder, S.K. (2000) "Role of Farakka Barrage on the Disastrous Flood at Malda (West Bengal) in 1998" Proc. 8th ICID Intl. Drainage Workshop 'Role of Drainage and Challenges of 21st Century Vol. III, sponsored by ICID -CIID \& Min. of Water Resources and org. by ICD \& WAPCOS, New Delhi Jan 31 - Feb 4, New Delhi

[13]. Mazumder, S.K. (2001) "Training of River Ganga Near Farakka Barrage: Proc. Of National conference on Hydraulics and Water Resources HYDRO -2001, org by Indian Soc. for Hydraulics (ISH) \& CWPRS, Pune, Dec. 6-7

[14]. Mazumder, S.K., Rastogi, S.P. and Hmar, Rofel (2002) "Restriction of Waterway under Bridges", J. of Indian Highways, Vol. 30, Nlo. 11, Nov.

[15]. Mazumder, S.K. and Dhiman, Rajni (2003), "Computation of afflux with particular reference to Widening of Bridges on roadway", Proc. National Conf. Of Hydraulics and Water Resources, HYDRO-2003, CW\&PRS, Pune, Dec.

[16]. Goswami, D. C., 1998. In Flood Studies in India, Geol. Soc. India, Bangalore, pp. 53-75.

[17]. Singh L., 2003. M. Tech. Dissertation: Morphological Analysis of Brahmaputra River Using Satellite Data and GIS”, WRDTC, IIT, Roorkee, India.

[18]. J. D. Das and A. K. Saraf, "Remote Sensing in the Map-ping of the Brahmaputra/Jamuna River Channel Patterns and Its Relation to Various Landforms and Tectonic En-vironment," International Journal of Remote Sensing, Vol. 28, No. 16, 2007, pp. 3619-3631. doi:10.1080/01431160601009664 